\title{
Polyvalent Human Immune Globulin: A Prospective, Open-Label Study Assessing Anti-Hepatitis A Virus (HAV) Antibody Levels, Pharmacokinetics, and Safety in HAV-Seronegative Healthy Subjects
}

\author{
Martin Kankam • Rhonda Griffin · Jeffrey Price · Josée Michaud • \\ Wei Liang • Mariona Bassas Llorens · Ana Sanz • Bradley Vince • \\ David Vilardell
}

Received: January 17, 2020 / Published online: April 16, 2020

(C) The Author(s) 2020

\section{ABSTRACT}

Background: Analytical data suggesting that immunoglobulin given intramuscularly (IGIM) may have reduced protection against hepatitis A virus (HAV) infection led to an update in the recommended IGIM dose $(0.2 \mathrm{ml} / \mathrm{kg})$.

Methods: This prospective, open-label, singlearm clinical study evaluated whether a single $0.2 \mathrm{ml} / \mathrm{kg}$ dose of IGIM provided protective levels of anti-HAV antibodies $(\geq 10 \mathrm{mIU} / \mathrm{ml}$ for up to 60 days) in $\mathrm{HAV}$-seronegative healthy adults.

Results: Of the 28 subjects enrolled and dosed, 26 (93\%) completed the study. Mean uncorrected anti-HAV antibody titers peaked at $109 \mathrm{mIU} / \mathrm{ml}$ on day 5 and stayed above $10 \mathrm{mIU} /$

Digital Features To view digital features for this article go to https://doi.org/10.6084/m9.figshare.11981613.

M. Kankam $(\bowtie) \cdot$ B. Vince

Altasciences/Vince and Associates, Overland Park, KS, USA

e-mail: MKankam@altasciences.com

R. Griffin · J. Price · W. Liang · M. B. Llorens Grifols Bioscience Research Group, Research

Triangle Park, NC, USA

J. Michaud

Altasciences Company Inc, Laval, QC, Canada

A. Sanz $\cdot$ D. Vilardell

Grifols Bioscience Industrial Group, Sant Cugat del

Vallès, Spain ml through day $60(N=26)$. The mean uncorrected anti-HAV antibody titers had a median $T_{\max }$ of $95.33 \mathrm{~h}$, a mean $C_{\max }$ of $118 \mathrm{mIU} / \mathrm{ml}$, and a mean observed $T_{\text {half }}$ of 63.3 days; baseline-corrected titers had a median $T_{\max }$ of $95.33 \mathrm{~h}$, a mean $C_{\max }$ of $114 \mathrm{mIU} / \mathrm{ml}$, and a mean observed $T_{\text {half }}$ of 47.1 days $(N=27)$. All subjects $(28 / 28)$ experienced at least 1 treatment-emergent adverse event (TEAE), with a total of 83 TEAEs reported; none was serious, and $96 \%(80 / 83)$ resolved without sequelae. Most (63\%) events judged definitely and possibly related to study treatment involved localized pain due to intramuscular injections. There were no serious adverse events and no deaths or discontinuations due to TEAEs.

Conclusions: A single $0.2 \mathrm{ml} / \mathrm{kg}$ dose of IGIM provided protective anti-HAV levels for at least 60 days, with acceptable safety and tolerability profiles in healthy subjects. Uncorrected and baseline-corrected pharmacokinetic findings were similar and consistent with the corresponding sampling points in previous research. Trial Registration: ClinicalTrials.gov Identifier, NCT03351933.

Keywords: Efficacy; Hepatitis A virus; Infectious diseases; Intramuscular immunoglobulin; Pharmacokinetics; Safety; Tolerability 


\section{Key Summary Points}

Why carry out this study?

Analytical data suggested that immunoglobulin given intramuscularly (IGIM) may have reduced protection against hepatitis A virus (HAV) infection.

Concerns about an association between the decreasing prevalence of previous HAV infection among plasma donors and declining anti-HAV antibody levels in donor plasma led to an update in the recommended IGIM dose $(0.2 \mathrm{ml} / \mathrm{kg})$.

We hypothesized that a single $0.2 \mathrm{ml} / \mathrm{kg}$ dose of IGIM would provide protective levels of antibodies to HAV (anti-HAV) for up to 60 days, with good safety and tolerability.

What was learned from the study?

Mean uncorrected anti-HAV antibody titers peaked at $109 \mathrm{mIU} / \mathrm{ml}$ on day 5 and stayed $>10 \mathrm{mIU} / \mathrm{ml}$ through day $60(\mathrm{~N}=$ 26).

A single $0.2 \mathrm{ml} / \mathrm{kg}$ dose of IGIM provided protective anti-HAV levels for at least 60 days, with acceptable safety and tolerability profiles in healthy subjects.

\section{INTRODUCTION}

Hepatitis $A$ is an infectious disease caused by the hepatitis A virus (HAV), a 27-nm picornavirus that infects humans after an incubation period of 14-28 days [1]. In 2000, the World Health Organization estimated that there were 1.5 million clinical cases of hepatitis A worldwide [2]; in 2015, it estimated the global burden of disease for hepatitis A fatalities at $0.8 \%$ $(n=11,000)$ [3]. Hepatitis A is usually acquired by the fecal-oral route and evolves rarely into fulminant hepatitis [4]. When symptoms are present, they generally resolve within
2 months, but some patients are affected for as long as 6 months. HAV-associated jaundice can progress to acute liver failure [5-7]. In the USA, $11 \%$ to $25 \%$ of reported hepatitis A cases $[8,9]$ require 4 days of hospitalization and 4 outpatient visits [9], resulting in the loss of work for 27 days. The risk of HAV-associated complications and hospitalization is highest in elderly patients [10-12].

Although there is no treatment for HAV infection, pre- and postexposure prophylaxis with the hepatitis A vaccine and/or immunoglobulin (IG) administered via the intramuscular route (IGIM) effectively prevents HAV infection [13-19]. Vaccination is recommended for individuals aged $\geq 12$ months, and IGIM is recommended for infants, people aged $\geq 40$ years, and those with chronic liver disease or in whom vaccination is contraindicated [16]. After the 2017 publication of data showing that IG manufactured from plasma donors with declining herd immunity to HAV yielded low anti-HAV IG potencies [20], concerns were raised about an association between the decreasing prevalence of previous HAV infection among plasma donors and declining antiHAV antibody levels in donor plasma. In response, IGIM dosing instructions were updated for international travel to areas with high or intermediate hepatitis A endemicity up to 1 month $(0.1 \mathrm{ml} / \mathrm{kg})$, up to 2 months $(0.2 \mathrm{ml} /$ $\mathrm{kg})$, and $\geq 2$ months ( $0.2 \mathrm{ml} / \mathrm{kg}$ every 2 months $)$ [16]. One formulation of IGIM (GamaSTAN, Grifols Therapeutics LLC, Research Triangle Park, NC, USA) is a sterile, preservative-free solution that can be used for prophylaxis against infection by HAV, measles, varicella, and rubella viruses, and it is the only IG product with an approved indication for HAV prophylaxis [21]. Unlike previous IG formulations, which relied on the solvent detergent method of viral inactivation, IGIM is manufactured from human plasma using a new purification scheme that employs caprylate/chromatography steps based on the processes of Cohn $[22,23]$ and Oncley [24]; the resulting IGIM is purer and more closely reflects the immunoglobulin $\mathrm{G}$ subclass distribution found in plasma $[25,26]$. The objectives of this study in HAV-seronegative healthy subjects were to 
evaluate whether a single $0.2 \mathrm{ml} / \mathrm{kg}$ dose of IGIM provides protective levels of antibodies to HAV (anti-HAV) for up to 60 days, assess the pharmacokinetic (PK) parameters of anti-HAV antibodies following a single $0.2 \mathrm{ml} / \mathrm{kg}$ IM dose of IGIM, and evaluate safety and tolerability.

\section{METHODS}

\section{Oversight}

Standards for Good Clinical Practice (GCP) were adhered to for all procedures in this study. The investigators ensured that the study was conducted in full conformance with appropriate local laws and regulations and the 1964 Helsinki Declaration and its later amendments or comparable ethical standards. The protocol and protocol amendments for this study were prepared in accordance with International Council for Harmonisation of Technical Requirements for Registration of Pharmaceuticals for Human Use (ICH) Guidelines (and any other relevant regulations). The protocol, protocol amendments, and informed consent form were reviewed and approved by the Midlands Institutional Review Board (Prairie Village, KS) prior to implementation. Regulatory approvals, authorizations, and notifications, where required, were in place and fully documented prior to study start. The Institutional Review Board had to supply to the sponsor, upon request, a list of members involved in the review and approval of the protocol, protocol amendments and consent form, and a statement to confirm that the IRB was organized and operating according to GCP Guidelines and applicable laws and regulations. Written informed consent for the complete study was obtained from each subject at the screening visit before any study-specific procedure took place. Participation in the study and date of informed consent given by the subject and/or legal representatives was documented appropriately in subjects' files. Subjects were given a copy of their signed and dated informed consent form.

\section{Study Conduct}

This prospective, single-arm, open-label study was conducted at a phase 1 clinical research unit (CRU) in the USA (Vince and Associates, Overland Park, KS) to assess the safety and tolerability of a single $0.2 \mathrm{ml} / \mathrm{kg}$ dose of IGIM in HAV-seronegative healthy subjects. The study was conducted in accordance with the Declaration of Helsinki, Good Clinical Practice guidelines of the International Conference on Harmonisation, as well as applicable regulatory requirements. MidLands Independent Review Board, Overland Park, KS, reviewed, approved, and monitored the study conduct. All subjects provided written informed consent before participating in the study.

The study included 14 visits. During the screening period (days -28 to -2 ), subjects provided informed consent and study personnel reviewed the eligibility criteria, documented the medical history and demographics, conducted clinical laboratory assessments, and performed safety assessments.

On day -1 , subjects were admitted to the CRU. The following assessments were performed: (1) eligibility review, (2) recording of concomitant medications and adverse events (AEs), (3) vital sign measurement, (4) clinical laboratory assessments, and (5) a symptom-directed physical examination and electrocardiogram (ECG). Subjects were housed in the CRU from day-1 (the day prior to the first dose administration [day 1]).

On day 1 , within 60 min before dosing, virus safety retention samples were collected, vital signs measured, and concomitant medications and AEs recorded. A single $0.2 \mathrm{ml} / \mathrm{kg}$ IGIM dose was administered, vital signs were measured before and after IGIM injection, and injection sites were evaluated post-IGIM administration. Furthermore, a PK blood sample was collected prior to treatment, $60 \mathrm{~min}$ postdose, and $12 \mathrm{~h}$ postdose.

On day 2, study personnel recorded concomitant medications and AEs, collected a PK blood sample, evaluated the injection sites, and performed a symptom-directed physical examination approximately $24 \mathrm{~h}$ after IGIM administration and prior to discharge from the CRU. 
On days $3,4,5,7,10,14,21,28,60,79$, and 115 , PK blood samples were collected, and concomitant medications and AEs were recorded. Additionally, on days 5, 28, and 60, vital signs were measured, and symptom-directed physical examinations and clinical laboratory assessments were conducted.

At the final visit (day 150)/early discontinuation visit, the following procedures were performed: (1) collection of PK blood sample and virus retention samples, (2) recording of concomitant medications and AEs, (3) full physical examination, (4) vital signs measurement, and (5) clinical laboratory assessments.

The total duration of study participation for subjects who completed the study was up to 178 days.

\section{Subjects}

Eligible subjects included healthy adults willing and able to provide written informed consent. Subjects of childbearing potential agreed to use an effective contraceptive; those of nonchildbearing potential had to be surgically sterile or in a menopausal state.

Subjects were excluded from participation if they were vaccinated against HAV, had positive anti-HAV antibodies in the blood sample, and had previously received any type of IG within the past 12 months prior to study treatment administration. Subjects with prolonged prothrombin time and activated partial thromboplastin time or with a platelet count < $100 \times 10^{9} / 1$ were also excluded. Furthermore, subjects were not eligible if they had any acute or chronic medical, surgical, or psychiatric significant condition or laboratory abnormality at screening or before treatment that might increase the risk associated with participation or administration of study treatment or interfere with the successful completion or interpretation of the study results.

\section{Treatments}

The study treatment was the GamaSTAN brand of polyvalent human IGIM, a clear to opalescent, colorless to pale yellow, sterile, $15-18 \%$ protein solution that contained a minimum of $20 \mathrm{IU} / \mathrm{ml}$ of anti-HAV antibodies with no preservative.

On day 1 , a single $0.2 \mathrm{ml} / \mathrm{kg}$ dose of IGIM was administered intramuscularly in the upper thigh or deltoid muscle of the nondominant arm or leg.

For each subject, the total volume of IGIM administered was prepared based on the subject's total body weight at screening. The number of injection sites was determined by the total volume of IGIM and a maximum injection volume of $5 \mathrm{ml}$ per injection site. Multiple injection sites were used to reduce local pain and discomfort.

\section{Selection of Doses}

An IGIM dose of $0.2 \mathrm{ml} / \mathrm{kg}$ was chosen because it is the recommended dose for prophylaxis prior to exposure to HAV for people traveling to endemic areas $[14,16,17]$. With the half-life of IGIM being approximately 23 days [21, 27], a 150-day follow-up period was chosen to cover approximately 5 half-lives.

\section{Assessments}

The primary efficacy variable was the proportion of subjects maintaining protective antiHAV antibody levels (defined as baseline-uncorrected anti-HAV antibody titer $\geq 10 \mathrm{mIU} / \mathrm{ml}$ in serum) after $T_{\max }$ up to 60 days following IGIM administration. The anti-HAV screening test was qualitative. At the day 1 visit and later time points, a quantitative anti-HAV test with a lower level of quantitation of $<4.00 \mathrm{mIU} / \mathrm{ml}$ was validated to determine the levels for the PK analysis. Total anti-HAV antibody levels in serum were measured throughout the study, and serum samples were analyzed by BioAgilytix Labs (Durham, NC, USA) via a validated enzyme immunoassay for the quantitation of anti-hepatitis A immunoglobulin in human serum.

The PK parameters of interest were area under the serum concentration time curve extrapolated to infinity $\left(\mathrm{AUC}_{0-\infty}\right)$; cumulative area under the serum concentration time curve 
from 0 to time of last observed quantifiable serum concentration $\left(\mathrm{AUC}_{0-T}\right) ;$ maximum observed serum concentration $\left(C_{\max }\right)$; time of maximum observed serum concentration $\left(T_{\max }\right)$; apparent elimination rate constant $(\lambda \mathrm{z})$; terminal elimination half-life ( $\left.T_{\text {half }}\right)$; apparent total serum clearance $\left(\mathrm{Cl}_{\mathrm{TOT}} / F\right)$, where $F$ is the systemic availability of the administered dose; and apparent volume of distribution $\left(V_{\mathrm{D}} / F\right)$, where $F$ is the systemic availability of the administered dose. Pharmacokinetic parameters were estimated using both anti-HAV antibody baseline-uncorrected and -corrected levels.

Safety variables in this study were AEs, which included serious AEs (SAEs); suspected adverse drug reactions (ADRs, defined as treatmentemergent AEs [TEAEs] judged either as definitely or possibly related to study treatment); and adverse reactions (ARs, defined as a suspected ADR for which there was a reason to conclude that the drug caused the event). Other safety variables included clinical laboratory parameters consisting of chemistry, hematology, and urinalysis; physical examination; and vital signs (heart rate, blood pressure [systolic and diastolic], respiration rate, and body temperature).

\section{Sample Size}

The sample size was chosen in agreement with the Food and Drug Administration (FDA) based on clinical considerations. A dropout rate of $30 \%$ was assumed, and it was estimated that 28 healthy subjects would need to be enrolled and treated to ensure an evaluable cohort of 20 subjects.

\section{Blinding}

No blinding or randomization scheme was implemented.

\section{Statistical Analysis}

The PK analyses were generated using Phoenix ${ }^{\circledR}$ WinNonlin $^{\circledR}$ version 8.0, Phoenix ${ }^{\circledR}$ Connect $^{\mathrm{TM}}$ version 1.3.1, and other statistical analyses were generated using SAS version 9.4 using the mixed procedure.
The efficacy analyses were performed on the evaluable population, which was defined as all subjects who received the entire IGIM dose and had no major protocol deviations that would have affected the efficacy analysis up to day 60 .

The PK analyses were performed on the PK population, which was defined as all subjects who received the entire IGIM dose and who provided sufficient serum concentration data to facilitate calculation of PK parameters. Blood samples were not retested for PK reasons in this study, and antibody titer values $<4.00 \mathrm{mIU} / \mathrm{ml}$ were set to zero. The PK parameters were derived from the anti-HAV antibody baselineuncorrected and -corrected serum concentrations (titers) versus time up to day 150 using noncompartmental analysis.

Safety analyses were performed on the safety population, which was defined as all subjects who received any amount of IGIM. Parameters included the incidence of AEs, suspected ADRs, ARs, clinical laboratory values, vital signs, and physical examination findings.

\section{RESULTS}

\section{Subjects}

In total, 28 subjects were enrolled and received IGIM. Subjects were enrolled between November 2017 and July 2018.

Of the 146 screened subjects (8 were rescreened), 28 were enrolled and received a single $0.2 \mathrm{ml} / \mathrm{kg}$ IGIM dose, and 93\% (26/28) of subjects completed the study (Fig. 1). As the IGIM volume injected at a single injection site could not exceed $5 \mathrm{ml}, 22$ subjects received 3 injections, and 6 subjects received 4 injections. Two subjects discontinued the study: 1 withdrew consent on day 54, and 1 was lost to follow-up on day 20.

The study population included 15 females and 13 males (Table 1). Most subjects were white $(64.3 \%, 18 / 28)$, and the safety population had a mean age of 41 years (range 22-61 years), a mean weight of $68.8 \mathrm{~kg}$ (range $52.1-99.5 \mathrm{~kg}$ ), and a mean body mass index of $23.51 \mathrm{~kg} / \mathrm{m}^{2}$ (range $19.4-28.2 \mathrm{~kg} / \mathrm{m}^{2}$ at enrollment). 


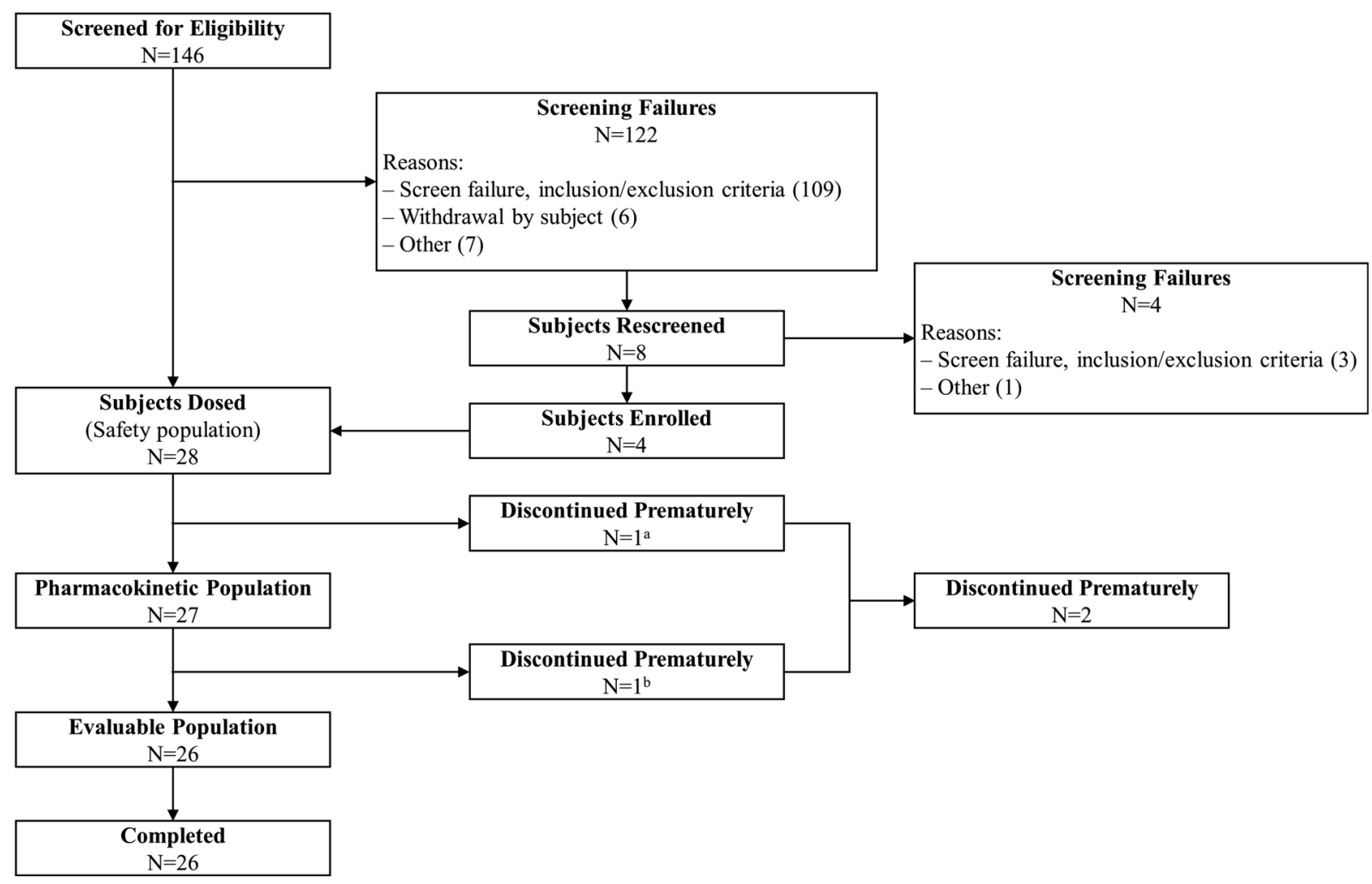

Fig. 1 Disposition of subjects. a Discontinued on day 54. b Discontinued on day 20

Of the 28 subjects enrolled, 26 who completed the study were included in the efficacyevaluable population. Two subjects who discontinued early had no anti-HAV titer data for multiple time points, including day 60 , and were excluded from the efficacy-evaluable population. Altogether, 27 subjects were included in the PK population, with 1 subject excluded because of early study discontinuation. Twentyeight subjects received IGIM and were included in the safety population.

Five subjects (18\%) received concomitant medications during the study. The most common concomitant medications were (1) acetaminophen for headache $(n=1)$, upper respiratory tract infection $(n=1)$, and influenza $(n=1)$ and (2) ibuprofen for headache and influenza $(n=1)$ and injection site reactionpain left thigh $(n=1)$. Other medications were used only by single subjects.

\section{Efficacy}

All 26 subjects achieved a baseline uncorrected anti-HAV antibody titer $>10 \mathrm{mIU} / \mathrm{ml}$ at day 60 . Following a single $0.2 \mathrm{ml} / \mathrm{kg}$ dose of IGIM, uncorrected anti-HAV antibody titers increased with peak mean titers occurring at day 5 (mean uncorrected titer $=109 \mathrm{mIU} / \mathrm{ml}$ ). Anti-HAV antibody titers decreased slightly after day 5 but maintained mean uncorrected levels above the protective threshold of $10 \mathrm{mIU} / \mathrm{ml}$ through day 60 , when the lower bound of the $90 \%$ CI was $22.5 \mathrm{mIU} / \mathrm{ml}$, and through day 115 .

Upon review, all 28 enrolled subjects were non-reactive in the qualitative assays for an anti-HAV test at screening; at baseline (day 1, predose), the anti-HAV antibody titer was $<10 \mathrm{mIU} / \mathrm{ml}$ for 26 subjects utilizing the quantitative assay. A post hoc baseline-corrected analysis with the predose concentration was performed. Baseline-corrected titers were $>$ $10 \mathrm{mIU} / \mathrm{ml}$ at day 60 for 24 of 26 subjects $(92.3 \%)$. Two subjects (7.7\%) had baseline- 
Table 1 Demographics and baseline characteristics (safety population, $N=28$ )

\begin{tabular}{lc}
\hline Sex, $n$ (\%) & \\
Female & $15(54)$ \\
Male & $13(46)$ \\
Childbearing potential, $n$ (\%) (females only) & \\
Yes & $5(33)$ \\
No & $10(67)$ \\
Race, $n$ (\%) & \\
White & $18(64)$ \\
Black or African American & $9(32)$ \\
American Indian or Alaska Native & $1(4)$ \\
Age, years, mean (SD) & $41(10)$ \\
Weight, kg, mean (SD) & $68.8(11.0)$ \\
Body mass index, kg/m ${ }^{2}$, mean (SD) & $23.5(2.1)$ \\
\hline
\end{tabular}

$S D$ standard deviation

corrected antibody titers below $10 \mathrm{mIU} / \mathrm{ml}$ at day 60 . Their corrected antibody titers were slightly below the protective threshold $(8.14 \mathrm{mIU} / \mathrm{ml}$ and $8.59 \mathrm{mIU} / \mathrm{ml}$, respectively), their baseline-uncorrected data were $>10 \mathrm{mIU} /$ $\mathrm{ml}$ at day $60(12.6 \mathrm{mIU} / \mathrm{ml}$ and $13.2 \mathrm{mIU} / \mathrm{ml}$, respectively) when the lower bound of the $90 \%$ confidence interval was 19.1 , and on day 28 titers were well above threshold $(33.0 \mathrm{mIU} / \mathrm{ml}$ and $46.9 \mathrm{mIU} / \mathrm{ml}$, respectively). The mean baseline-corrected anti-HAV antibody titers were similar to the uncorrected titers and are summarized in Table 2.

\section{Pharmacokinetics}

Fourteen antibody titer values were set to missing for the PK analysis due to early termination by 2 subjects.

For baseline-corrected PK data, mean $C_{\max }$ was $114 \mathrm{mIU} / \mathrm{ml}$, median $T_{\max }$ was $95.33 \mathrm{~h}$ (range $47.00-312.52 \mathrm{~h}$ ), mean $\mathrm{AUC}_{0-T}$ was $98,100 \mathrm{mIU}{ }^{*} \mathrm{~h} / \mathrm{ml}$, mean $T_{\text {half }}$ observed was 47.1 days, mean $\mathrm{Cl}_{\mathrm{TOT}} / F$ was $2.57 \mathrm{ml} / \mathrm{h}$, the mean $V_{\mathrm{D}} / F$ was $4180 \mathrm{ml}$, and the $T_{\text {half }}$ using a truncated schedule at day 28 was 30.5 days. The mean $\mathrm{AUC}_{0-\infty}$ with the truncated data at day 28 was similar to values obtained at day 150 $\left(114,000 \mathrm{~h}^{*} \mathrm{mIU} / \mathrm{ml}\right.$ and $112,000 \mathrm{~h}^{*} \mathrm{mIU} / \mathrm{ml}$, respectively). Concentration versus time profiles are presented in linear and semi-logarithmic scales for uncorrected (Fig. 2) and baselinecorrected (Fig. 3) values.

Results for uncorrected and baseline-corrected PK parameters are shown in Tables 3, 4, and 5. For uncorrected data, the mean $C_{\max }$ of the anti-HAV antibody was $118 \mathrm{mIU} / \mathrm{ml}$, and the median $T_{\max }$ was $95.33 \mathrm{~h}$ (range $47.0-312.5 \mathrm{~h}$ ). The mean $\mathrm{AUC}_{0-\mathrm{T}}$ was 112,000 $\mathrm{mIU} * \mathrm{~h} / \mathrm{ml}$. The mean $T_{\text {half }}$ observed was 63.3 days, the mean $\mathrm{Cl}_{\mathrm{TOT}} / F$ was $2.17 \mathrm{ml} / \mathrm{h}$, and the mean $V_{\mathrm{D}} / F$ was $4790 \mathrm{ml}$. In addition, $T_{\text {half }}$ values obtained in nonprespecified analyses using a truncated schedule at day 28 (sampling up to 28 days) was 28.5 days. The mean $\mathrm{AUC}_{0-\infty}$ with the truncated data at day 28 $\left(116,000 \mathrm{~h}{ }^{*} \mathrm{mIU} / \mathrm{ml}\right)$ was similar to the uncorrected value at day $150\left(136,000 \mathrm{~h}^{*} \mathrm{mIU} / \mathrm{ml}\right)$.

\section{Safety}

Eighty-three TEAEs were reported for all 28 subjects who received a single $0.2 \mathrm{ml} / \mathrm{kg}$ IGIM dose. The TEAEs that occurred in at least 2 subjects are summarized in Table 6. Overall, the most frequently reported TEAE was injection site pain, with $71 \%(20 / 28)$ of subjects experiencing 52 events. The onset of the injection site pain TEAEs ranged from immediately after IGIM administration to $23 \mathrm{~h}$ postdose with a duration ranged between $1 \mathrm{~min}$ and 7 days. The remaining TEAEs were headache $(18 \%$ [5/28] of subjects, 5 events); vascular access site hemorrhage (7\% of subjects [2/28], 3 events); and neutrophil count decreased, white blood cell count decreased, and nasal congestion (7\% [2/28] subjects, 2 events each). Most TEAEs were mild ( $82 \%$ [23/28] of subjects, 78 events), but $18 \%$ (5/ 28 ) of subjects had moderate TEAEs of vertigo, upper respiratory tract infection, skin lesion, headache, and injection site pain. No SAEs were reported. 
Table 2 Serum anti-HAV titers at day 60 (evaluable population, $N=26$ )

\begin{tabular}{lll}
\hline Parameter, $\mathbf{~ m I U / \mathbf { m } ^ { \mathbf { a } }}$ & Baseline corrected & Uncorrected \\
\hline Mean (SD) & $21.8(8.0)$ & $25.7(9.6)$ \\
Minimum & 8.1 & 11.1 \\
Median & 22.4 & 26.2 \\
Maximum & 37.0 & 41.7 \\
CV\% & 36.8 & 37.2 \\
$90 \%$ CI lower mean & 19.1 & 22.5 \\
$90 \%$ CI upper mean & 24.4 & 28.9 \\
Geometric mean & 20.2 & 23.8 \\
\hline
\end{tabular}

Two subjects were excluded from the efficacy-evaluable population

$C V \%$ coefficient of variation, $S D$ standard deviation, $C I$ confidence interval

${ }^{a}$ Values at the lower limit of quantitation $(<4.00 \mathrm{mIU} / \mathrm{ml})$ were set to 0 for descriptive statistics and noncompartmental analysis

Altogether, 79\% (22/28) of subjects had 55 TEAEs that were considered definitely related to the study treatment; $18 \%$ of these subjects (4/ 22) also experienced 6 TEAEs that were judged possibly related to the study treatment. Six subjects (21\%) experienced 22 TEAEs that were unrelated to the study treatment. The incidence of suspected ADRs (TEAEs definitely/possibly related to treatment) was $78.6 \%(22 / 28)$ and was largely driven by the number of injection siterelated reactions. The most frequently experienced suspected ADR was injection site pain (71\%, 20/28 subjects, 52 events); injection site hemorrhage and injection site reaction were each reported in 1 of 28 subjects (4\%). The only other suspected ADR reported by at least 2 subjects was headache $(7 \%, 2 / 28,2$ events). All other suspected ADRs (fatigue, influenza, paraesthesia, somnolence, and nasal congestion) were reported by 1 subject $(3.6 \%, 1 / 28)$.

A total of 3 TEAEs of moderate severity that were unrelated to study treatment remained unresolved at the end of the study. One subject experienced vertigo on day 140 , received a chiropractic adjustment on day 142, and had a normal physical examination at the final visit; vertigo was still present on day 153 , with no change in frequency or severity from its initial occurrence, and the subject confirmed being followed by a chiropractor. A second subject was exposed to a child with strep throat, developed an upper respiratory tract infection on day 148, and began concomitant treatment with antibiotics; at follow-up (day 158), the infection was still ongoing, and symptoms were stable. A third subject reported a clinically significant skin lesion (dark plaque type) on the right upper arm on day 53 that was treated with topical antibiotics and improved but remained unresolved at the final visit on day 148. At follow-up (day 158), the lesion persisted with no change in severity from its initial appearance. No deaths occurred during the study. Additionally, there were no study discontinuations due to AEs or SAEs and no hypersensitivity events related to IGIM.

Clinically significant findings in laboratory parameters and physical examinations were associated with TEAEs during the study, but none were related to study treatment. There were no clinically significant findings in vital signs.

\section{DISCUSSION}

In this study, the primary efficacy objective was to evaluate whether a single $0.2 \mathrm{ml} / \mathrm{kg}$ dose of IGIM provided protective levels of anti-HAV antibodies in HAV-seronegative healthy 

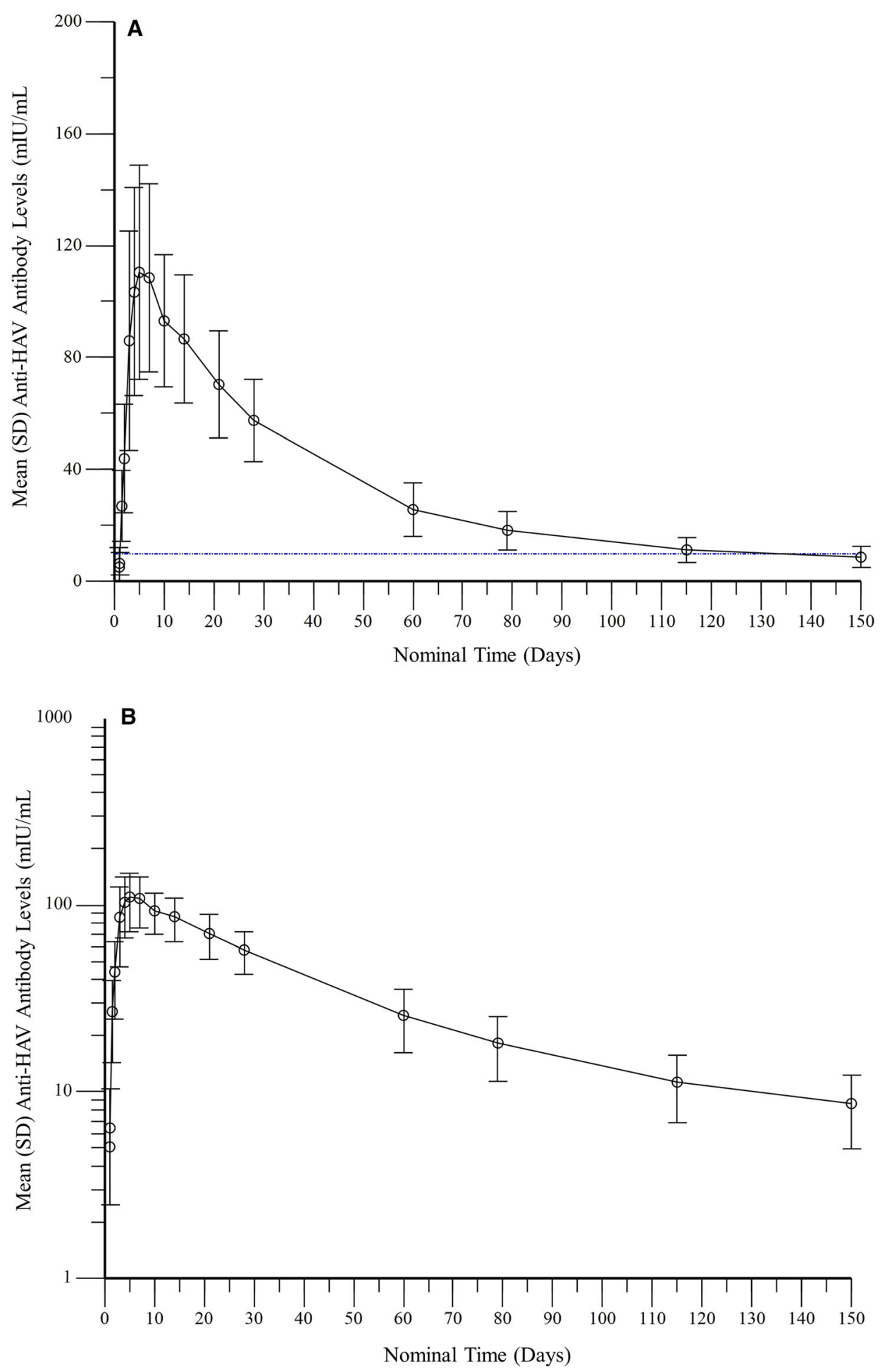

Fig. 2 Mean serum uncorrected concentration-time profile of anti-HAV antibody following a single $0.2 \mathrm{ml} / \mathrm{kg}$ dose of IGIM on linear (a) and semi-log (b) scales (PK population). $H A V$ hepatitis A virus, IGIM immunoglobulin via intramuscular injection. The blue reference line is set at the protective threshold of $10 \mathrm{mIU} /$ $\mathrm{ml}$ 

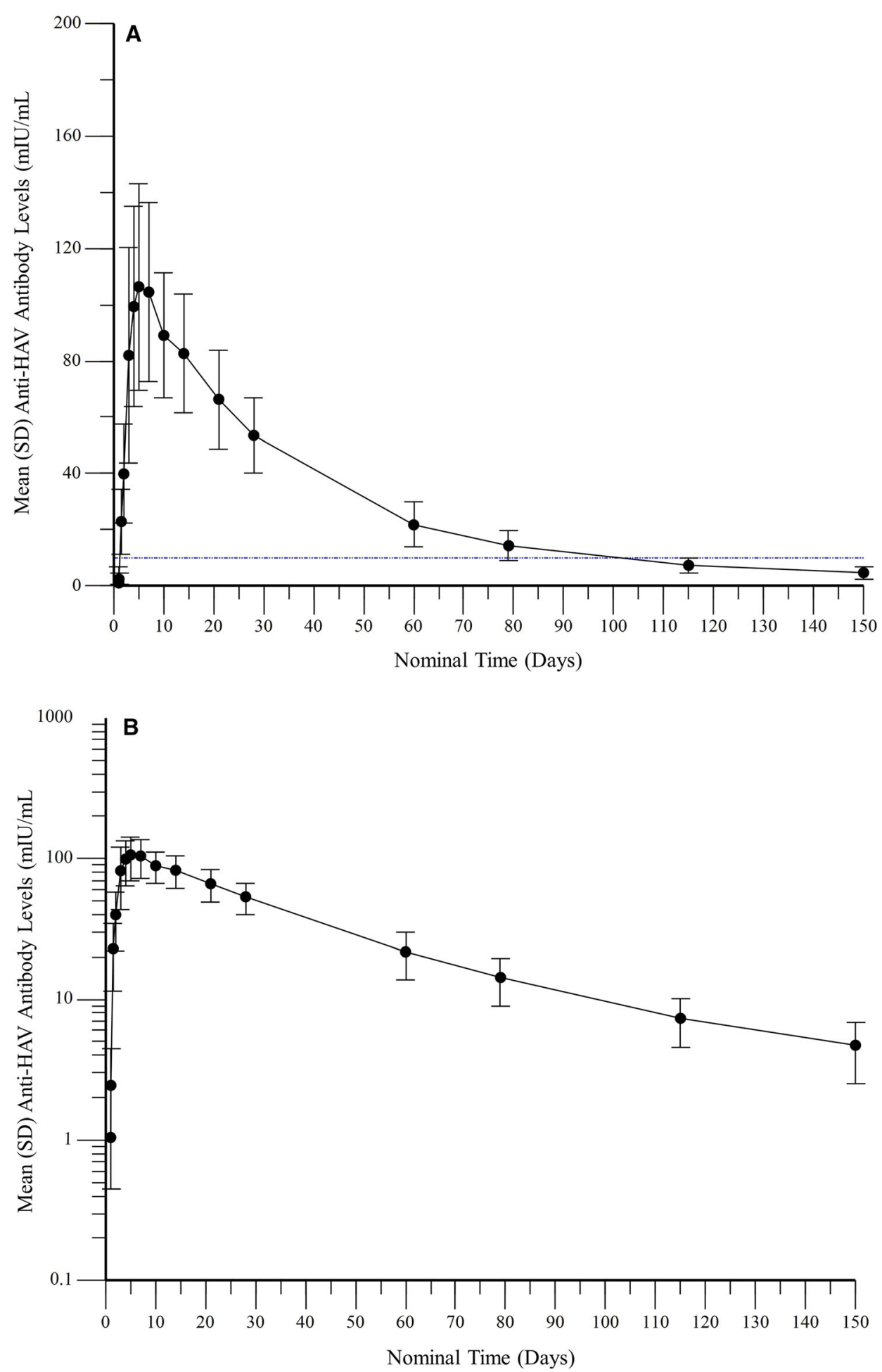

Fig. 3 Mean serum baseline-corrected concentration-time profile of anti-HAV antibody following a single $0.2 \mathrm{ml} / \mathrm{kg}$ dose of IGIM on linear (a) and semi-log (b) scales (PK population). $H A V$ hepatitis A virus, IGIM immunoglobulin via intramuscular injection. The blue reference line is set at the protective threshold of $10 \mathrm{mIU} / \mathrm{ml}$ 
Table 3 Uncorrected pharmacokinetic parameters for anti-HAV antibody (PK population, $N=27$ )

\begin{tabular}{|c|c|c|c|c|c|c|c|c|c|}
\hline & $\begin{array}{l}\mathrm{AUC}_{\mathbf{0}-\infty} \\
\left(\mathrm{h}^{*} \mathrm{mIU} / \mathrm{ml}\right)\end{array}$ & $\begin{array}{l}\mathrm{AUC}_{0-T} \\
\left(\mathrm{~h}^{*} \mathrm{mIU} / \mathrm{ml}\right)\end{array}$ & $\begin{array}{l}C_{\max } \\
(\mathrm{mIU} / \\
\mathrm{ml})\end{array}$ & $\begin{array}{l}T_{\max } \\
(\mathbf{h})\end{array}$ & $\begin{array}{l}T_{\text {half }} \\
\text { (h) }\end{array}$ & $\begin{array}{l}\mathrm{Cl}_{\mathrm{TOT}} / \\
\boldsymbol{F}(\mathbf{m l} / \mathbf{h})\end{array}$ & $\begin{array}{l}V_{\mathrm{D}} / \\
F(\mathrm{ml})\end{array}$ & $\lambda_{\mathrm{Z}}(1 / \mathrm{h})$ & $T_{\text {half }}^{a}(\mathrm{~h})$ \\
\hline$N$ & 26 & 27 & 27 & 27 & 26 & 26 & 26 & 26 & 14 \\
\hline Mean & 136,000 & 112,000 & 118 & 116.02 & 1520 & 2.17 & 4790 & 0.0005 & 683 \\
\hline SD & 38,700 & 30,200 & 40.0 & 55.34 & 545 & 0.694 & 2490 & 0.0001 & 269 \\
\hline Minimum & 64,700 & 56,600 & 61.8 & 47.00 & 949 & 1.10 & 2500 & 0.0002 & 295 \\
\hline Median & 133,000 & 111,000 & 119 & 95.33 & 1330 & 1.99 & 3940 & 0.0005 & 621 \\
\hline Maximum & 215,000 & 165,000 & 248 & 312.52 & 2940 & 4.08 & 13,700 & 0.0007 & 1200 \\
\hline CV\% & 28.4 & 27.1 & 33.8 & 47.7 & 35.8 & 32.0 & 52.0 & 26.5 & 39.3 \\
\hline $\begin{array}{r}\text { CI } 90 \% \\
\text { lower } \\
\text { mean }\end{array}$ & 123,000 & 102,000 & 105 & 97.9 & 1340 & 1.94 & 3950 & 0.000454 & 556 \\
\hline $\begin{array}{r}\text { CI } 90 \% \\
\text { upper } \\
\text { mean }\end{array}$ & 149,000 & 121,000 & 131 & 134 & 1710 & 2.40 & 5620 & 0.000542 & 810 \\
\hline $\begin{array}{c}\text { Geometric } \\
\text { mean }^{\mathrm{b}}\end{array}$ & 131,000 & 107,000 & 113 & 107 & 1450 & 2.07 & 4330 & 0.000478 & 635 \\
\hline
\end{tabular}

$H A V$ hepatitis A virus, $S D$ standard deviation, $C V \%$ coefficient of variation, $C I$ confidence interval

${ }^{\text {a }}$ Estimated with a truncated sampling schedule of 28 days

b Calculated by the exponential of the mean of $\log ($ concentration $)$ values

subjects for up to 60 days. The results show that all IGIM-treated subjects (100\%) in the efficacy population achieved an uncorrected anti-HAV antibody titer $>10 \mathrm{mIU} / \mathrm{ml}$ starting at $12 \mathrm{~h}$ postdose and continuing through day 60 . The majority of baseline-corrected titers (92.3\%) were also maintained above $10 \mathrm{mIU} / \mathrm{ml}$ through day 60. Mean anti-HAV antibody titers remained above the protective threshold of $10 \mathrm{mIU} / \mathrm{ml}$ through day 60 , with the lower bound of the $90 \% \mathrm{CI}>10 \mathrm{mIU} / \mathrm{ml}$. In the 2 IGIM-treated subjects who had baseline-corrected antibody levels below the protective threshold levels, it is important to note that their baseline uncorrected data were $>10 \mathrm{mIU} /$ $\mathrm{ml}$ at day $60(12.6 \mathrm{mIU} / \mathrm{ml}$ and $13.2 \mathrm{mIU} / \mathrm{ml}$, respectively), and on day 28 titers were well above threshold $(33.0 \mathrm{mIU} / \mathrm{ml}$ and $46.9 \mathrm{mIU} /$ $\mathrm{ml}$, respectively).

The safety and tolerability of IGIM manufactured using a new method were as expected, and most AEs were due to injection site-related reactions. Injection site hemorrhage and injection site reaction were reported each in 1 subject. Two suspected ADRs of headache were reported. No systemic hypersensitivity, thrombotic, or other potential for serious reactions associated with normal immunoglobulins (e.g., renal dysfunction or hemolysis) were reported in this study. These results align with the known safety profile of the previous IGIM manufactured method, for which injection site pain and inflammation, headache, and fatigue adverse reactions as well as others were reported during the postmarketing surveillance [21].

The absolute lower limit of anti-HAV IgG required to prevent $\mathrm{HAV}$ infection has not been defined, but $10 \mathrm{mIU} / \mathrm{ml}$ is recognized as the lowest effective dose for providing the minimal protection for HAV prophylaxis [28]. The minimum anti-HAV IgG potency is at least $100 \mathrm{IU} /$ $\mathrm{ml}$ [29]. After a 2017 study showed that few 
Table 4 Baseline-corrected pharmacokinetic parameters for anti-HAV antibody (PK population, $N=27$ )

\begin{tabular}{|c|c|c|c|c|c|c|c|c|c|}
\hline & $\begin{array}{l}\mathrm{AUC}_{\mathbf{0}-\infty} \\
\left(\mathrm{h}^{*} \mathrm{mIU} / \mathrm{ml}\right)\end{array}$ & $\begin{array}{l}\mathrm{AUC}_{0-T} \\
\left(\mathrm{~h}^{*} \mathrm{mIU} / \mathrm{ml}\right)\end{array}$ & $\begin{array}{l}C_{\max } \\
(\mathrm{mIU} / \mathrm{ml})\end{array}$ & $\begin{array}{l}T_{\max } \\
\text { (h) }\end{array}$ & $\begin{array}{l}T_{\text {half }} \\
\text { (h) }\end{array}$ & $\begin{array}{l}\mathrm{Cl}_{\mathrm{TOT}} / \\
F(\mathbf{m l} / \mathbf{h})\end{array}$ & $\begin{array}{l}V_{\mathrm{D}} / \\
F(\mathrm{ml})\end{array}$ & $\lambda_{\mathrm{Z}}(\mathbf{1} / \mathbf{h})$ & $\begin{array}{l}T_{\text {half }}{ }^{2} \\
\text { (h) }\end{array}$ \\
\hline$N$ & 26 & 27 & 27 & 27 & 26 & 26 & 26 & 26 & 11 \\
\hline Mean & 112,000 & 98,100 & 114 & 116.02 & 1130 & 2.57 & 4180 & 0.0007 & 731 \\
\hline SD & 26,700 & 23,400 & 38.3 & 55.34 & 561 & 0.679 & 2610 & 0.0003 & 226 \\
\hline Minimum & 52,900 & 52,700 & 61.8 & 47.00 & 427 & 1.77 & 1900 & 0.0002 & 486 \\
\hline Median & 116,000 & 97,100 & 114 & 95.33 & 1010 & 2.49 & 3180 & 0.0007 & 662 \\
\hline Maximum & 180,000 & 136,000 & 241 & 312.52 & 2840 & 4.08 & 13,700 & 0.0016 & 1100 \\
\hline CV\% & 23.8 & 23.8 & 33.5 & 47.7 & 49.8 & 26.4 & 62.4 & 41.3 & 30.9 \\
\hline $\begin{array}{l}\text { CI 90\% lower } \\
\text { mean }\end{array}$ & 103,000 & 90,500 & 102 & 97.9 & 938 & 2.34 & 3310 & 0.000638 & 607 \\
\hline $\begin{array}{r}\text { CI } 90 \% \\
\text { upper } \\
\text { mean }\end{array}$ & 121,000 & 106,000 & 127 & 134 & 1310 & 2.80 & 5060 & 0.000843 & 854 \\
\hline $\begin{array}{c}\text { Geometric } \\
\text { mean }^{\mathrm{b}}\end{array}$ & 109,000 & 95,200 & 109 & 107 & 1020 & 2.49 & 3670 & 0.000679 & 702 \\
\hline
\end{tabular}

$H A V$ hepatitis A virus, $S D$ standard deviation, $C V \%$ coefficient of variation, $C I$ confidence interval

${ }^{a}$ Estimated with a truncated sampling schedule of 28 days

${ }^{b}$ Calculated by the exponential of the mean of $\log ($ concentration) values

commercially available IG preparations met these specifications [20], a new anti-HAV titer specification of at least $10 \mathrm{IU} / \mathrm{ml}$ was approved and instituted for IGIM [16], and dosing instructions for hepatitis. Pre- and post-exposure prophylaxis indications were updated $[16,17]$. In response, Grifols committed to performing a clinical study with an IGIM purified using a new manufacturing method to ensure that the level of protection met the newly instituted anti-HAV specification. The results of the present study demonstrate that IGIM provided protective anti-HAV levels of at least $20 \mathrm{IU} / \mathrm{ml}$ for at least 60 days.

Information on IG product titers and antibody levels after passive immunization to prevent hepatitis $A$ in humans is scarce, mainly because successful prophylaxis of hepatitis A with IG was demonstrated long before the 1973 discovery of HAV [30]. In 1945, for example, a $0.3 \mathrm{ml} / \mathrm{kg}$ dose of IGIM was shown to be protective during a hepatitis A outbreak in a summer camp [31], and in 1954, a dose of $0.01 \mathrm{ml} /$ $\mathrm{kg}$ was found to be near the minimal effective dose during an outbreak in a closed institution [32]; both reports used IG with unknown antiHAV antibody content. A prospective study published in 1991 reported results in $23 \mathrm{HAV}$ seronegative subjects who were passively immunized with standard doses $(0.016-0.022 \mathrm{ml} / \mathrm{kg})$ of a hepatitis A IG preparation containing $100 \mathrm{IU}$ anti-HAV/ml that produced anti-HAV antibody levels of $21 \mathrm{mIU} /$ $\mathrm{ml}$ at day 4 after administration [33]. A 1993 prospective study $(N=49)$ of anti-HAV antibody levels after passive immunization with $5 \mathrm{ml}$ IGIM alone found that the geometric mean titer was $96 \mathrm{mIU} / \mathrm{ml}$ day $5,58 \mathrm{mIU} / \mathrm{ml}$ at month $1,22 \mathrm{mIU} / \mathrm{ml}$ at month $2,1 \mathrm{mIU} / \mathrm{ml}$ at month 5 , and not detectable at month 6 [34].

Pharmacokinetic parameters for IGIM were generally predictable and in line with the results of previous research. However, the uncorrected $T_{\text {half }}$ was longer than the baseline-corrected $T_{\text {half }}$ (63 days vs 47 days), and both $T_{\text {half }}$ values were longer than the mean $T_{\text {half }}$ (22-27 days) 
Table 5 Exposure to IGIM (safety population, $N=28$ )

Total volume prepared, $\mathrm{ml}$

$\begin{array}{ll}\text { Mean (SD) } & 13.76(2.202) \\ \text { Median } & 13.55 \\ \text { Min, max } & 10.4,19.9 \\ \text { Total volume administrated, ml } & \end{array}$

$\begin{array}{ll}\text { Mean (SD) } & 13.76(2.202) \\ \text { Median } & 13.55 \\ \text { Min, max } & 10.4,19.9\end{array}$

Treatment compliance, ${ }^{a} \%$

$\begin{array}{ll}\text { Mean }(S D) & 100.0(0.00) \\ \text { Median } & 100.0 \\ \text { Min, max } & 100,100\end{array}$

Duration of treatment administration, min

\begin{tabular}{ll} 
Mean (SD) & $1.3(0.70)$ \\
Median & 1.0 \\
Min, max & 0,3 \\
Injection site, ${ }^{\mathrm{b}} n(\%)$ & \\
Left upper arm & $18(64)$ \\
Left upper thigh & $28(100)$ \\
Right upper arm & $20(71)$ \\
Right upper thigh & $24(86)$ \\
\hline
\end{tabular}

IGIM immunoglobulin via intramuscular injection, $S D$ standard deviation

${ }^{a}$ Total volume administered divided by total volume prepared multiplied by $100 \%$

${ }^{\mathrm{b}}$ Includes $>1$ injection site per subject per treatment

reported for other IGIM (not HAV-specific) with sampling days from 28 to 35 days [35-37]. This likely occurred because of shorter sampling data periods in previously reported data and the fact that for each subject with different $T_{\text {half }}$ values, the terminal slope of the corrected concentration versus time curve in the log scale was steeper than the uncorrected curve. The variance in terminal slope had the effect of increasing corrected $\lambda_{z}$ values, which were
Table 6 Treatment-emergent adverse events occurring in at least two subjects (safety population, $N=28$ )

\begin{tabular}{lll}
\hline Event, $\boldsymbol{n}$ (\%) & $\begin{array}{l}\text { Subjects }^{\mathbf{a}} \\
(\boldsymbol{N}=\mathbf{2 8})\end{array}$ & $\begin{array}{l}\text { Events } \\
\left(\boldsymbol{N}=\mathbf{8 3}^{\mathbf{b}}\right)\end{array}$ \\
\hline Any TEAE & $28(100)$ & $83(100)$ \\
$\begin{array}{l}\text { General disorders and } \\
\text { administration site } \\
\text { conditions }\end{array}$ & $22(79)$ & $55(66)$ \\
Injection site pain & $20(71)$ & $52(63)$ \\
$\begin{array}{l}\text { Injury, poisoning and } \\
\text { procedural complications }\end{array}$ & $3(11)$ & $4(5)$ \\
$\begin{array}{l}\text { Vascular access site } \\
\text { hemorrhage }\end{array}$ & $2(7)$ & $3(4)$ \\
$\begin{array}{l}\text { Investigations } \\
\text { Neutrophil count decreased }\end{array}$ & $2(7)$ & $2(2)$ \\
$\begin{array}{l}\text { White blood cell count } \\
\text { decreased }\end{array}$ & $2(7)$ & $2(2)$ \\
Nervous system disorders & $6(21)$ & $7(8)$ \\
Headache & $5(18)$ & $5(6)$ \\
Respiratory, thoracic and & $2(7)$ & $2(2)$ \\
mediastinal disorders & $2(7)$ & $2(2)$ \\
Nasal congestion & & \\
\hline
\end{tabular}

$T E A E$ treatment-emergent adverse event

${ }^{\text {a }}$ Each subject is counted only once for each level of summary

b Total number of TEAEs is the denominator for all percentages in the events column

estimated by linear regression of the terminal linear portion of the log concentration versus time curve, and reducing the corrected $T_{\text {half, }}$ which was calculated as $\ln 2 / \lambda_{z}$. It is also possible that the negligible target-mediated elimination of IgGs in this study was a factor-subjects were not suffering from the infection-even accounting for the heterogeneity of IgG and its wide distribution of half-lives. In addition, various IgG subclasses may interact differently with Fc receptors (which prolong $T_{\text {half }}$ ) differently, as glycosylation and other post-translational modifications can also affect binding to Fc 
receptors. Consequently, the longer sampling in the present study may have skewed the calculated result towards the longer $T_{\text {half }}$ IgG subsets. A post hoc truncated $T_{\text {half }}$ analysis at day 28 was similar to values reported previously in the literature (baseline-corrected $T_{\text {half }}$ of 30.5 days and baseline-uncorrected $T_{\text {half }}$ of 28.5 days).

In this study, a single $0.2 \mathrm{ml} / \mathrm{kg}$ IM IGIM dose was shown to be safe and well tolerated, with all TEAEs mild or moderate in intensity, most $(71 \%)$ related to injection site pain, and the vast majority (96\%) resolved without sequelae at the end of follow-up. The assessment of safety did not reveal any new safety signals or a pattern of clinically relevant changes in laboratory parameters, and any abnormalities recorded during the study were consistent with those that might reasonably be expected with the use of polyclonal IGs.

Limitations of this study include the small number of subjects and the use of a surrogate efficacy outcome. The sample size was appropriate to assess PK. A study assessing clinical outcomes would have required the recruitment of an unfeasibly large number of subjects to be appropriately powered to detect a clinically meaningful and statistically significant difference. In addition, because the Advisory Committee on Immunization Practices recommends HAV vaccination for prophylaxis for travelers aged at least 12 months, whereas IGIM is recommended for prophylaxis only in infants, adults aged at least 40 years, individuals with chronic liver disease, and those with a contraindication to HAV vaccination [16], the generalizability of these findings is limited.

Studies determining whether the protective antibody threshold is clinically relevant would be necessary to allow the design and conduct of well-controlled studies in the hepatitis A preand post-exposure prophylaxis setting. The efficacy of hepatitis A prophylaxis with passive immunization has been historically demonstrated, but there are no recent studies devoted to assessment of specific high-risk populations. As a result, most of the data on the effectiveness of passive immunization for pre- and post-exposure hepatitis A prophylaxis come from studies performed long ago with a risk of bias, highlighting the need for new research using strong clinical outcomes and modern methodologic standards. At the same time, due to the nature of this treatment, using placebo control group comparisons in clinical studies would pose significant ethical and logistical concerns for future clinical developments. This could potentially be addressed by using appropriate PK/pharmacodynamics modeling and simulation methods once protective thresholds have been confirmed.

\section{CONCLUSIONS}

Following a single dose of $0.2 \mathrm{ml} / \mathrm{kg}$ IGIM, all 26 subjects in the evaluable population achieved anti-HAV uncorrected titers $>10 \mathrm{mIU} / \mathrm{ml}$ after $T_{\max }$ through day 60 . For mean baseline-corrected values, anti-HAV antibody titers showed a $T_{\max }$ of $95.33 \mathrm{~h}$, a $C_{\max }$ of $114 \mathrm{mIU} / \mathrm{ml}$, and an observed $T_{\text {half }}$ of $1130 \mathrm{~h}$ (47.1 days). For mean uncorrected values, anti-HAV antibody titers rose rapidly following a single $0.2 \mathrm{ml} / \mathrm{kg}$ dose of IGIM to reach a median $T_{\max }$ at $95.33 \mathrm{~h}$ with a mean $C_{\max }$ of $118 \mathrm{mIU} / \mathrm{ml}$ and observed mean $T_{\text {half }}$ of $1520 \mathrm{~h}$ (63.3 days). A single $0.2 \mathrm{ml} / \mathrm{kg}$ IGIM dose was safe and well tolerated in HAVseronegative healthy adults.

\section{ACKNOWLEDGEMENTS}

The authors wish to acknowledge the clinical study participants for their participation, the vendors for their collaborations, and internal Grifols team members who contributed to the clinical study conduct. Specifically, the authors would like to thank the following individuals for their many contributions to the clinical study conduct: Beatriz Garcia (Grifols), Barbara Merrill (Grifols), Henry Li (Grifols), Junliang Chen (Grifols), Glenn Stephenson (Grifols), Pete Vandeberg (Grifols), Cameron Binnie (Grifols), Jeff Heinzman (Altasciences Company), Anastasia Papageorgiou (Altasciences Co.), and LaToya McElrath (BioAgilytix).

Funding. This study, medical writing services, and the Rapid Service and Open Access 
Fees were funded by Grifols Bioscience Research Group.

Medical Writing Assistance. Christopher Caiazza of Polymedia Corporation provided medical writing services by assisting in the preparation and revision of the manuscript, tables, and figures under the direction of the authors. This medical writing assistance was funded by Grifols.

Authorship. All named authors meet the International Committee of Medical Journal Editors (ICMJE) criteria for authorship for this article, take responsibility for the integrity of the work as a whole, and have given their approval for this version to be published.

Authorship Contributions. All authors contributed to the design of the study and were involved in the acquisition, analysis, and interpretation of data, as well as in the drafting and revising of the manuscript for important intellectual content. All authors also ensured that questions related to the accuracy or integrity of any part of the work were appropriately investigated and resolved.

Disclosures. Martin Kankam, Josée Michaud, and Bradley Vince are employed by Altasciences Inc., which receives compensation from the Grifols Bioscience Research Group, manufacturer of the GamaSTAN brand of polyvalent human IGIM. Rhonda Griffin, Jeffrey Price, Wei Liang, Mariona Bassas Llorens, Ana Sanz, and David Vilardell are employed by Grifols Bioscience Research Group.

Compliance with Ethics Guidelines. Standards for Good Clinical Practice (GCP) were adhered to for all procedures in this study. The investigators ensured that the study was conducted in full conformance with appropriate local laws and regulations and the 1964 Helsinki Declaration and its later amendments or comparable ethical standards. The protocol and protocol amendments for this study were prepared in accordance with International Council for Harmonisation of Technical Requirements for Registration of Pharmaceuticals for Human
Use (ICH) Guidelines (and any other relevant regulations). The protocol, protocol amendments, and informed consent form were reviewed and approved by the Midlands Institutional Review Board (Prairie Village, KS) prior to implementation. Regulatory approvals, authorizations, and notifications, where required, were in place and fully documented prior to study start. The Institutional Review Board had to supply to the sponsor, upon request, a list of members involved in the review and approval of the protocol, protocol amendments and consent form, and a statement to confirm that the IRB was organized and operating according to GCP Guidelines and applicable laws and regulations. Written informed consent for the complete study was obtained from each subject at the Screening visit before any study-specific procedure took place. Participation in the study and date of informed consent given by the subject and/or legal representatives was documented appropriately in subjects' files. Subjects were given a copy of their signed and dated informed consent form.

Data Availability. The datasets generated during and/or analyzed during the current study are not publicly available for proprietary reasons, but they may be made available from the corresponding author upon reasonable request.

Open Access. This article is licensed under a Creative Commons Attribution-NonCommercial 4.0 International License, which permits any non-commercial use, sharing, adaptation, distribution and reproduction in any medium or format, as long as you give appropriate credit to the original author(s) and the source, provide a link to the Creative Commons licence, and indicate if changes were made. The images or other third party material in this article are included in the article's Creative Commons licence, unless indicated otherwise in a credit line to the material. If material is not included in the article's Creative Commons licence and your intended use is not permitted by statutory regulation or exceeds the permitted use, you will need to obtain permission directly from the copyright holder. To view a copy of this licence, 
visit http://creativecommons.org/licenses/by$\mathrm{nc} / 4.0 /$.

\section{REFERENCES}

1. Krugman S, Giles JP. Viral hepatitis. New light on an old disease. JAMA. 1970;212(6):1019-29.

2. Hepatitis A. Hepatitis A vaccines. Wkly Epidemiol Rec. 2000;75(5):38-44.

3. GBD 2015 Mortality and Causes of Death Collaborators. Global, regional, and national life expectancy, all-cause mortality, and cause-specific mortality for 249 causes of death, 1980-2015: a systematic analysis for the Global Burden of Disease Study 2015. Lancet. 2016;388(10053):1459-544. https://doi.org/10.1016/S0140-6736(16)31012-1.

4. Klevens RM, Miller JT, Iqbal K, Thomas A, Rizzo EM, Hanson $\mathrm{H}$, et al. The evolving epidemiology of hepatitis $\mathrm{a}$ in the United States: incidence and molecular epidemiology from population-based surveillance, 2005-2007. Arch Intern Med. 2010;170(20):1811-8. https://doi.org/10.1001/ archinternmed.2010.401.

5. Fujiwara K, Yokosuka O, Ehata T, Saisho H, Saotome N, Suzuki K, et al. Association between severity of type A hepatitis and nucleotide variations in the 5' non-translated region of hepatitis A virus RNA: strains from fulminant hepatitis have fewer nucleotide substitutions. Gut. 2002;51(1):82-8.

6. Chi H, Haagsma EB, Riezebos-Brilman A, van den Berg AP, Metselaar HJ, de Knegt RJ. Hepatitis A related acute liver failure by consumption of contaminated food. J Clin Virol. 2014;61(3):456-8. https://doi.org/10.1016/j.jcv.2014.08.014.

7. Yoshida Y, Okada Y, Suzuki A, Kakisaka K, Miyamoto Y, Miyasaka A, et al. Fatal acute hepatic failure in a family infected with the hepatitis A virus subgenotype IB: a case report. Medicine (Baltimore). 2017;96(35):e7847. https://doi.org/10.1097/ md.0000000000007847.

8. Centers for Disease Control and Prevention. Hepatitis surveillance report no. 56, 1996. Available at: https://stacks.cdc.gov/view/cdc/23149. Accessed 12 Mar 2020.

9. Collier MG, Tong X, Xu F. Hepatitis A hospitalizations in the United States, 2002-2011. Hepatology. 2015;61(2):481-5. https://doi.org/10.1002/hep. 27537.
10. Willner IR, Uhl MD, Howard SC, Williams EQ, Riely CA, Waters B. Serious hepatitis A: an analysis of patients hospitalized during an urban epidemic in the United States. Ann Intern Med. 1998;128(2): $111-4$.

11. Brown GR, Persley K. Hepatitis A epidemic in the elderly. South Med J. 2002;95(8):826-33.

12. Chau TN, Lai ST, Tse C, Ng TK, Leung VK, Lim W, et al. Epidemiology and clinical features of sporadic hepatitis E as compared with hepatitis A. Am J Gastroenterol. 2006;101(2):292-6. https://doi.org/ 10.1111/j.1572-0241.2006.00416.x.

13. Novak R, Bell B. Update: Prevention of hepatitis A after exposure to hepatitis A virus and in international travellers. Updated recommendations of the Advisory Committee on Immunization Practices (ACIP). MMWR Morb Mortal Wkly Rep. 2007;56(41):1080-4.

14. Fiore AE, Wasley A, Bell BP. Prevention of hepatitis A through active or passive immunization: recommendations of the Advisory Committee on Immunization Practices (ACIP). MMWR Recomm Rep. 2006;55(RR-07):1-23.

15. Nelson NP (2017) Hepatitis A. In: CDC Yellow Book 2018 Health Information for International Travel. Oxford University Press, New York

16. Nelson NP. Updated dosing instructions for immune globulin (human) GamaSTAN S/D for hepatitis A virus prophylaxis. MMWR Morb Mortal Wkly Rep. 2017;66(36):959-60. https://doi.org/10. 15585/mmwr.mm6636a5.

17. Nelson NP, Link-Gelles R, Hofmeister MG, Romero $\mathrm{JR}$, Moore KL, Ward JW, et al. Update: recommendations of the Advisory Committee on Immunization practices for use of hepatitis A vaccine for postexposure prophylaxis and for preexposure prophylaxis for international travel. MMWR Morb Mortal Wkly Rep. 2018;67(43):1216-20. https://doi. org/10.15585/mmwr.mm6743a5.

18. Liu JP, Nikolova D, Fei Y. Immunoglobulins for preventing hepatitis A. Cochrane Database Syst Rev. 2009;2:CD004181. https://doi.org/10.1002/ 14651858.CD004181.pub2.

19. Victor JC, Monto AS, Surdina TY, Suleimenova SZ, Vaughan G, Nainan OV, et al. Hepatitis A vaccine versus immune globulin for postexposure prophylaxis. N Engl J Med. 2007;357(17):1685-94. https:// doi.org/10.1056/NEJMoa070546.

20. Tejada-Strop A, Costafreda M, Dimitrova Z, Kaplan GG, Teo C. Evaluation of potencies of immune globulin products against hepatitis a. JAMA Intern 
Med. 2017;177(3):430-2. https://doi.org/10.1001/ jamainternmed.2016.9057.

21. Prescribing information: GAMASTAN ${ }^{\circledR}$ [immune globulin (human)], solution for intramuscular injection. Available at: https://www.fda.gov/media/ 86789/download. Accessed 12 Mar 2020.

22. Cohn EJ, Strong LE, et al. Preparation and properties of serum and plasma proteins; a system for the separation into fractions of the protein and lipoprotein components of biological tissues and fluids. J Am Chem Soc. 1946;68:459-75.

23. Cohn EJ, Gurd FRN, Surgenor DM, Barnes BA, Brown RK, Derouaux G, et al. A system for the separation of the components of human blood: quantitative procedures for the separation of the protein components of human plasma1a, b, c. J Am Chem Soc. 1950;72(1):465-74. https://doi.org/10. 1021/ja01157a122.

24. Oncley JL, Melin M, Richert DA, Cameron JW, Gross PM. The separation of the antibodies, isoagglutinins, prothrombin, plasminogen and $\beta 1$ lipoprotein into subfractions of human plasma. J Am Chem Soc. 1949;71(2):541-50. https://doi. org/10.1021/ja01170a048.

25. Barnette D, Roth NJ, Hotta J, Cai K, Gall M, Hartwell R, et al. Pathogen safety profile of a $10 \%$ IgG preparation manufactured using a depth filtrationmodified process. Biologicals. 2012;40(4):247-53. https://doi.org/10.1016/j.biologicals.2012.04.003.

26. Lebing W, Remington KM, Schreiner C, Paul HI. Properties of a new intravenous immunoglobulin (IGIV-C, 10\%) produced by virus inactivation with caprylate and column chromatography. Vox Sang. 2003;84(3):193-201.

27. Waldmann TA, Strober W, Blaese RM. Variations in the metabolism of immunoglobulins measured by turnover rates. In: Merler E, editor. Immunoglobulins: biologic aspects and clinical uses. Washington: National Academy of Sciences; 1970. p. 33-51.

28. Kroger AT, Duchin JS, Vázquez M. General best practice guidelines for immunization: best practices guidance of the Advisory Committee on Immunization Practices (ACIP). Available at: https:// www.cdc.gov/vaccines/hcp/acip-recs/general-recs/ index.html. Accessed 12 Mar 2020.
29. Council of Europe. European pharmacopoeia. 8th ed. Strasbourg: Council of Europe; 2015.

30. Feinstone SM, Kapikian AZ, Purcell RH. Hepatitis A: detection by immune electron microscopy of a viruslike antigen associated with acute illness. Science. $\quad 1973 ; 182(4116): 1026 . \quad$ https://doi.org/10. 1126/science.182.4116.1026.

31. Neefe JR, Stokes J Jr. An epidemic of infectious hepatitis apparently due to a water borne agent: epidemiologic observations and transmission experiments in human volunteers. JAMA. 1945;128(15):1063-75. https://doi.org/10.1001/ jama.1945.02860320005003.

32. Drake ME, Ming C. Gamma globulin in epidemic hepatitis: comparative value of two dosage levels, apparently near the minimal effective level. JAMA. 1954;155(15):1302-5.

33. Viral Hepatitis and Liver Disease (1991) Proceedings of the 1990 international symposium on viral hepatitis and liver disease: contemporary issues and future prospects. Williams Wilkins, Baltimore.

34. Zaaijer HL, Leentvaar-Kuijpers A, Rotman H, Lelie PN. Hepatitis A antibody titres after infection and immunization: implications for passive and active immunization. J Med Virol. 1993;40(1):22-7.

35. Smith GN, Griffiths B, Mollison D, Mollison PL. Uptake of IgG after intramuscular and subcutaneous injection. Lancet. 1972;1(7762):1208-12.

36. Jilma-Stohlawetz P, Reiter RA, Panzer S, Horvath M, Eppel W, Jilma B. Pharmacokinetics (PK) of S/D treated anti-D immunoglobulin after intramuscular injection in healthy volunteers: gender differences in PK. Transfus Apher Sci. 2005;33(2):135-40. https://doi.org/10.1016/j.transci.2005.02.006.

37. Filipponi F, Franchello A, Carrai P, Romagnoli R, De Simone P, Woodward MK, et al. Efficacy, safety, and pharmacokinetics of intramuscular hepatitis B immune globulin, Igantibe, for the prophylaxis of viral $B$ hepatitis after liver transplantation. Dig Liver Dis. 2010;42(7):509-14. https://doi.org/10. 1016/j.dld.2009.09.005. 